\title{
The expression profile of PKC isoforms during MC3T3-E1 differentiation
}

\author{
J.D. LAMPASSO ${ }^{1}$, WEN CHEN ${ }^{2}$ and N. MARZEC ${ }^{2}$ \\ Departments of ${ }^{1}$ Oral Biology and Orthodontics, ${ }^{2}$ Oral Biology, University of Buffalo, Buffalo, NY 14214, USA
}

Received January 9, 2006; Accepted March 13, 2006

\begin{abstract}
Protein kinase C (PKC) is a family of kinases whose isoforms show subtle differences in physiological and biochemical responses, with their expression being cellspecific. We hypothesize that there may be a specific profile of expression of PKC isoforms in differentiating osteoblastic cells (OBC) with individual isoforms having specific functions. Herein, the MC3T3-E1 cell line was used as a differentiating model, which was induced from the pre-osteoblast stage to mature osteoblast and characterized with several phenotypic markers, including alkaline phosphatase activity, osteocalcin and bone sialoprotein. The expression of PKC isoforms was monitored using Western blot analysis. Upon induction of osteogenesis, the intracellular localization of PKC $\eta$ and $\theta$ was determined using immunofluorescence. Lastly, the effect of P38 MAP kinase inhibition was determined using SB203580. Results show 1) PKC $\alpha, \delta, \lambda$ were all highly expressed in MC3T3-E1 osteoblastic cells, 2) the expression of PKC $\theta$ was significantly down-regulated upon induction of osteoblastic differentiation; 3) PKC $\eta$ was non-detectable at certain cell culture days; however, was up-regulated as the cells transit from each differentiation phase. The increased expression of PKC $\eta$ correlated with increases in OC, BSP levels and alkaline phosphatase activity. Immunofluorescence procedure confirmed the Western blot results with an increase in PKC $\eta$ and a decrease in PKC $\theta$ upon osteogenic stimulation. The inhibition of $\mathrm{p} 38$ resulted in a marked downregulation of PKC $\eta$. The data demonstrate that there is a specific profile of expression of PKC isoforms in differentiating osteoblasts; the different expression pattern of individual isoforms may be either a consequence of the differentiation itself or plays a role in the regulatory mechanism of osteoblastic differentiation. This study has provided primary information on the temporal pattern of expression of PKC isoforms in the differentiating osteoblast and further insight into their possible role in osteoblastic cell maturation.
\end{abstract}

Correspondence to: Dr Judith Lampasso, 322 Foster Hall, SUNY at Buffalo, 3435 Main Street, Buffalo, NY 14214, USA

E-mail: lampasso@acsu.buffalo.edu

Key words: osteoblast, MC3T3-E1, protein kinase C isoform, differentiation, bone sialoprotein

\section{Introduction}

The osteoblastic cell (OBC) line, MC3T3-E1 cells, derived from newborn mouse calvaria develops in a sequential manner into the mature osteoblast phenotype $(1,2)$. It was demonstrated that the MC3T3-E1 in vitro cell system, with proper stimulation, has the capability to become osteoblastic, and form calcified bone tissue (3). The pattern of expression of bonerelated proteins in MC3T3-E1 OBC occurs in a temporal manner similar to that of the rat calvaria osteoblastic cell model $(1,4)$. This cell system has proven to be a useful tool in studying osteoblastic cell differentiation $(5,6)$.

The role of p38 MAP kinase in stress responses and apoptosis has been well documented. There is growing evidence for the role of $\mathrm{p} 38$ in cellular differentiation. The inhibition as well as the activation of p38 has affirmed a role for $\mathrm{p} 38$ in adipocytic differentiation (7). In myocytes, the stimulation of muscle-specific gene expression by p38 has been shown to be mediated by myocyte enhancer factor- $2 \mathrm{C}$ (MEF2C) transcription factor, a known p38 substrate (8). The role of p38 in osteoblastic cells is now being delineated but there are conflicting results on the effect of p38 on OBC differentiation. The activation as well as specific inhibition of p38 has been demonstrated to both increase and decrease OBC protein markers $(9,10)$. In these contrasting results, the cells were stimulated with different agents as well as inhibited with different concentration of SB203580, a specific p38 inhibitor. Recent studies in our laboratory demonstrated that SB203580 exerted a lasting inhibitory effect on p38 in primary human as well as MC3T3-E1 cells during the early stages of $\mathrm{OBC}$, leading to a marked decrease in alkaline phosphatase activity in response to differentiating factors (11).

Protein kinase $\mathrm{C}$ is a ubiquitous enzyme that has been shown to be involved in a number of cellular processes $(12,13)$. The eleven isoforms that make up the PKC family are classified as a result of enzymatic and molecular analyses into three major classes; the conventional calcium-dependent isoforms (cPKCs $\alpha, \beta I, \beta I I$ and $\gamma$ ) the novel calcium independent isoforms (nPKC $\delta, \varepsilon, \lambda / \mathrm{l}, \eta$ and $\theta$ ) and the atypical isoform $(\mathrm{aPKC} \varsigma)$. There exists specificity in the pattern of expression as a well as activation for the different isoforms, suggesting that each play an important role in tissue-specific functions (14-17). In the osteoblast, PKC has been shown to be an important component in the signal transduction pathways involving the response of the cell to various processes of proliferation and differentiation $(18,19)$. 
The expression of PKC isoforms has been demonstrated in several types of osteoblastic cells (20-22). The number of studies is limited in regards to PKC isoforms in MC3T3-E1 cells. Sakai et al demonstrated that PKC $\alpha$ was the major calcium-dependent isoform expressed in MC3T3-E1 cells (23); however, this study evaluated only the isoforms from the conventional, calcium-dependent class. A comprehensive determination of those isoforms of PKC present in MC3T3-E1 OBC has yet to be elucidated. The aim of the present study was to determine the profile expression of PKC isoforms during osteoblastic cell differentiation and to correlate them with the expression pattern of bone-related proteins to gain a better understanding of the signals involved in the differentiation process. This approach allows for a better understanding of the molecular systems involved in the signal transduction mechanism of osteogenesis.

\section{Materials and methods}

Cell cultures. MC3T3-E1 cells were placed in culture consisting of $\alpha$-MEM (Gibco, Grand Island, NY) $+10 \%$ fetal bovine serum and $1 \%$ antibiotic and maintained until cells were needed. Cells were sub-cultured in osteogenic media ( $\alpha$-MEM supplemented with $10 \mathrm{mM} \beta$-glycerophosphate, $50 \mathrm{mM}$ ascorbic acid and $10 \mu \mathrm{M}$ dexamethasone) for the induction of the osteoblast phenotype. Cells were cultured for 1-23 days at $37^{\circ} \mathrm{C}$ in $5 \% \mathrm{CO}_{2}$. The effect of the inhibition of P38 on osteoblastic cell differentiation was determined by treating the osteoblastic cell cultures with $10 \mu \mathrm{M}$ of SB203580 (Sigma, St. Louis, MD) for four days. After day 4, the cell cultures were continued in osteogenic media for the remainder of culture period.

\section{Identification of osteoblast differentiation}

Alkaline phosphatase activity. On the required day of culture, MC3T3 cells were sub-cultured in osteogenic media for the induction of the osteoblast phenotype. The cells were seeded in a 96-well culture plate and incubated to confluency. The media in each well was removed and replaced with $200 \mu \mathrm{l}$ of $1 \%$ Triton-X-100 for $1 \mathrm{~h}$ at $4^{\circ} \mathrm{C}$ in order to lyse the cells. Lysate $(100 \mu \mathrm{l})$ was then taken from each well and $50 \mu \mathrm{l}$ of p-nitrophenol phosphate and $50 \mu 1$ of 2-amino-2methyl-1propanol buffer were added. The alkaline phosphatase reaction was run for $90 \mathrm{~min}$ at $37^{\circ} \mathrm{C}$ and stopped with the addition of $0.5 \mathrm{M} \mathrm{NaOH}$. The absorbance of the samples was read at $405 \mathrm{nM}$ with a spectrophotometer and a standard curve was generated with p-nitrophenol solutions with $0.02 \mathrm{M} \mathrm{NaOH}$. A Sigma unit of phosphatase activity was defined as the amount of enzyme activity that will liberate $1 \mu$ mole of p-nitrophenol per hour under the test conditions described in detail by Bessey (24). Values were expressed as Sigma units/mg protein. Protein was measured with the remaining $100 \mu 1$ of lysate in each well using a BioRad protein assay (Bio-Rad Laboratories, NY, USA).

Reverse transcriptase-polymerase chain reaction ( $R T-P C R)$. Total RNA was extracted from MT3C3-E1 cell cultures from day 1-23 at an interval of two days using TRIzol total RNA isolation reagent (Invitrogen Life Technologies, Inc., Rockville, MD). The first-strand cDNA was synthesized from $1 \mu \mathrm{g}$ of total RNA by using the SuperScript III ${ }^{\mathrm{TM}}$ RNase

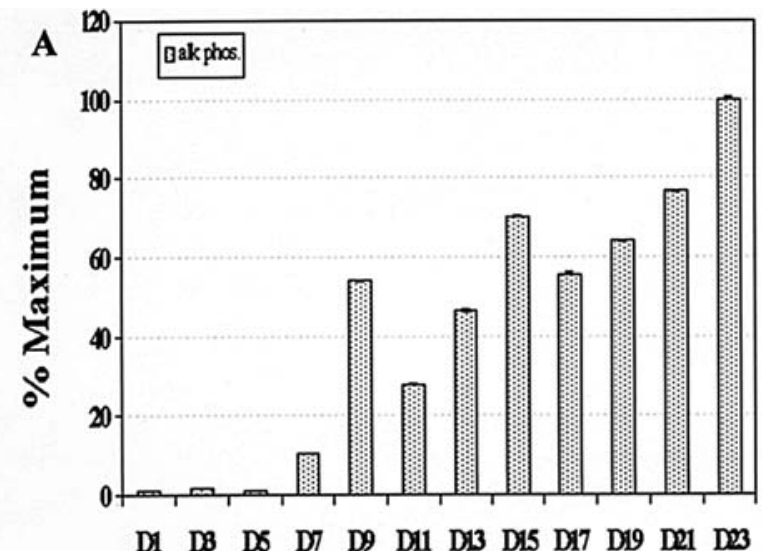

Days in culture

B

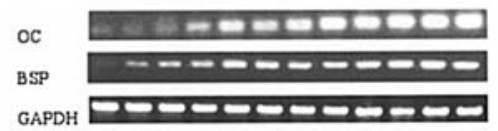

Figure 1. Protein markers of OBC differentiation. Cells were cultured and induced as indicated in Materials and methods. (A) Alkaline phosphatase activity from the MC3T3-E1 osteoblastic cells was measured using a spectro-photometric assay. Results are presented as the percentage maximum degree of alkaline phosphatase activity. Data represent the mean Sigma units/mg protein and SD of quadruplicate samples. (B) The expression of OC and BSP in MC3T3-E1 osteoblastic cells. Semiquantitative RT-PCR was preformed on RNA extracted from the sample at indicated days. Each blot is representative of 3 separate experiments with similar results.

H-reverse transcriptase (Invitrogen Life Technologies, Inc.). Using the cDNA as a template, PCR was carried out under the following conditions: denaturation at $94^{\circ} \mathrm{C}$ for $45 \mathrm{sec}$, annealing at $58^{\circ} \mathrm{C}$ for $45 \mathrm{sec}$ and primer extension at $72^{\circ} \mathrm{C}$ for $90 \mathrm{sec}$ in 25 cycles for GAPDH, osteocalcin and bone sialoprotein. Pairs of oligonucleotides, 5'-GTCCCGTAGAC AAAATGGTG-3' and 5'-AGGCCCCTCCTGTTATTATG-3' for GAPDH, 5'-ACCTAGCAGACACCATGAGG-3' and 5'-TACTTGCAGGGCAGAGAGAG-3' for osteocalcin, 5'-AT TCTGAAGAAAACGGGGTC-3' and 5'-CGTCCTCATAA GCTCGGTAA-3' for bone sialoprotein, were used as primers for RT-PCR. The PCR products were separated in $1 \%$ agar gels and stained with ethidium bromide. The fragment bands were quantified by using the GS700 imaging densitometer (Bio-Rad).

Morphological staging. MC3T3-E1 osteoblast-like cells obtained at different times (every two days) in culture were washed in PBS (3x). The cells were fixed for $5 \mathrm{~min}$ in neutral formalin then rinsed with deionized water. The wells were exposed to UV light after the addition of 5\% silver nitrate. Sodium thiosulfate was used to stop the treatment after $1 \mathrm{~h}$.

Determination of PKC isoform expression

Western blot analysis. MC3T3-E1 osteoblast-like cells from day 1-23 (at an interval of two days in culture) were isolated 
A

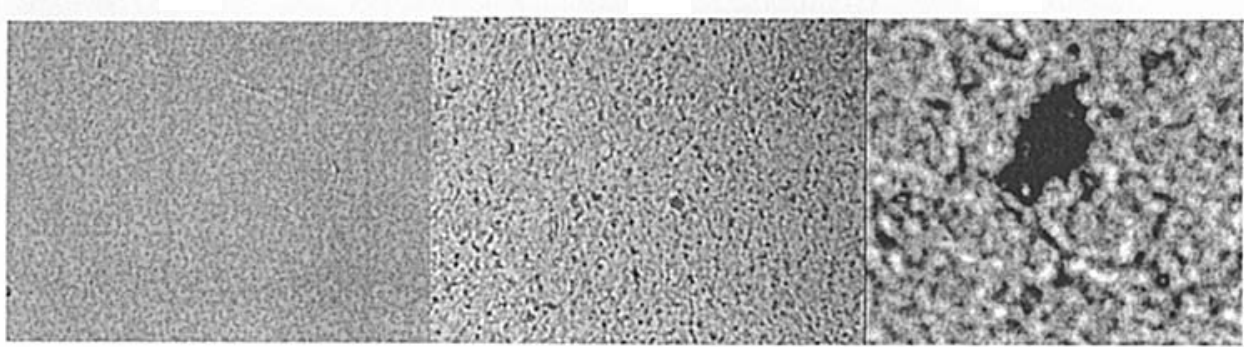

early mid

\section{late}

Figure 2. Morphologic changes of the culture. MT3C3-E1 cells were cultured and induced from day 1 to 23 as indicated in the text. The cultures were examined and micrographed at a two-day interval (A, early) initial proliferative stage (Day 1); (B, mid) differentiation stage (Day 9); (C, late) mineralization stage (Day 21).

as follows: The cells were collected from the wells in $1 \mathrm{X}$ cold PBS, counted and an equal number of cells were then solubilized using $100 \mu \mathrm{l}$ SDS sample buffer (2\% SDS, 10 mM DTT, $10 \%$ glycerol, $10 \mathrm{mM}$ Tris- $\mathrm{HCl}, 0.01 \%$ bromophenol blue) for each condition. The collected cell number was kept constant throughout the experiment. Western blot analyses using commercially available antibodies were performed in order to determine the PKC isoforms expressed in MC3T3-E1. Whole cell lysate samples were analyzed along with prestained standards (commercially available from Bio-Rad) and PKC isoform positive control (rat cerebrum from Transduction Laboratories, Lexington, KY) on 7.5\% sodium dodecyl sulfate polyacrylamide gel (SDS-PAGE) at $\sim 200 \mathrm{~V}$, constant current. After electrophoresis, the proteins were transferred to Immobilon $\mathrm{P}$ membranes at $47 \mathrm{~mA}$ constant current for $90 \mathrm{~min}$. The membranes with the transferred proteins were blocked in PBS with $3 \%$ milk for $60 \mathrm{~min}$ in order to prevent the non-specific adsorption of the antibodies. The membranes were then probed with specific primary antibodies to PKC $\alpha, \beta, \gamma, \delta, \varepsilon, \lambda / \eta$ and $\theta$ (Transduction Laboratories) diluted to the recommended concentrations for at least $1 \mathrm{~h}$. After appropriate washing steps, the membranes were then incubated with hrp conjugate goat anti-mouse $\operatorname{IgG}$ as the second antibody at a 1:2000 dilution for at least $1 \mathrm{~h}$. Detection of the proteins that were expressed was achieved by placing the membrane in a chemiluminescent mixture for $5 \mathrm{~min}$ then exposed to Kodak film. Quantification of the isoforms expressed was determined by densitometry.

Immunofluorescence. Intracellular localization of PKC $\eta$ and $\theta$ was determined using an immunofluorescence cell staining procedure. MC3T3 cells grown in osteogenic and non-osteogenic media were allowed to attach to cover slips for $24 \mathrm{~h}$. After appropriate washes, the cells were fixed with $2 \%$ formaldehyde, permeabilized, and blocked for non-specific binding. The cells were incubated with monoclonal primary antibody to PKC $\eta$ and $\theta$ followed by incubation with FITC conjugated secondary antibody. Each coverslip was then mounted onto a slide containing mounting media. A phase contrast fluorescence microscope (Nikon Eclipse inverted microscope TE 2000-U) with appropriate filters was then used to observe the intracellular localization of the PKC $\eta$ and $\theta$ of stimulated and non-stimulated cells.
Morphology. MC3T3-E1 osteoblast-like cells obtained at different times (every two days) in culture were washed in PBS (3x). The cells were fixed for $5 \mathrm{~min}$ in neutral formalin, then rinsed with deionized water. The cells were exposed to UV light after the addition of 5\% silver nitrate. Sodium thiosulfate was used to stop the treatment after $1 \mathrm{~h}$.

Statistical analysis. All alkaline phosphatase spectrophotometric assays were preformed in quadruplicate and repeated for inter-sample verification. Results were expressed as the percentage maximum degree of activity. Statistical analyses were performed using a statistical software program (StatView 4.5, Cary, NC). Data were analyzed by factorial analysis of variance (ANOVA). The level of significance corresponded to a P-value of $\leq 0.05$.

\section{Results}

Expression of OBC differentiation markers by MC3T3-E1 cells. It was determined that the expression pattern of osteoblastic cell differentiation markers was similar to previously published reports. Alkaline phosphatase activity was minimal at days 1-7 in culture with a significant increase in activity observed at days 9, 15 and 21 (Fig. 1A). Levels of OC were low at days 1-5. At day 5 of osteogenic stimulation, the level of OC began to rise with significant increases observed at days 9 and 15 (Fig. 1B). The expression pattern for bone sialoprotein (BSP) was very similar to that of OC. The mRNA level of BSP was low at day 1 and continually increased in expression with a significant peak observed at day 9. BSP reached a peak level of mRNA expression from day 17 to day 23 (Fig. 1B). In our observation, the initial critical time-dependent changes appeared to occur consistently between days 7 and 9 , following stimulation with osteogenic media. The next critical timedependent change occurred around days 15 and 17 cultured in osteogenic media and the final phase occurred around day 21. We observed a significant increase in the expression levels of these markers approximately every seven days, suggesting the transition of the cells from the proliferationdifferentiation-mineralization phase.

Morphologic changes of the cell culture. The initial period of culture displayed flat elongated cells resembling fibroblasts (Fig. 2A). After 7-9 days of osteogenic stimulation, the cell 
culture exhibited characteristic post mitotic differentiating osteoblasts involved in matrix accumulation (Fig. 2B). However, Von Kossa staining was not positive for mineralizing nodules until days 19-21, indicating the presence of mature non-proliferating OBC (Fig. 2C).

Expression pattern of PKC isoforms in MC3T3-E1 osteoblastic cells. The expression of PKC $\alpha, \beta, \gamma, \delta, \varepsilon, \lambda, \eta$ and $\theta$ in MC3T3-E1 osteoblastic cells was determined using commercially available isoform-specific antibodies with Western blotting. The amount of total protein was accounted for by standardizing the number of cells used during each series of experiments. Whole cell lysate protein obtained from MC3T3-E1 cells was run on SDS-PAGE along with standards and controls. PKC $\alpha, \delta, \lambda, \eta$ and $\theta$ are all highly expressed in MC3T3-E1 osteoblastic cells. The isoforms $\beta$ and $\varepsilon$ were minimally detectable, showing low reactivity as compared to PKC positive control (rat cerebrum). PKC $\gamma$ was not detected under any of the culture conditions used. The pattern of expression for all five major isoforms detected in MC3T3-E1 is such that all are highly expressed during the early proliferative phase of $\mathrm{OBC}$ differentiation. However, as time in culture increased, there were differences observed in the expression pattern of the different isoforms as it relates to the maturing $\mathrm{OBC}$, with $\mathrm{PKC} \eta$ and $\theta$ displaying the most interesting pattern of expression in differentiating MC3T3 cells (Fig. 3).

Correlation of the effect of osteogenic media on differentiation markers and PKC $\theta$ and $\eta$ expression in MC3T3-E1 cells. The pattern of expression of PKC $\eta$ and $\theta$ was therefore correlated to the $\mathrm{OBC}$ protein differentiating markers in order to better decipher their expression profile. The level of PKC $\eta$ was highest at day 1 of cells cultured in OG media with a dramatic decrease in expression thereafter. The level of PKC $\eta$ decreased to as low as $25 \%$ at day 5 . An increase in PKC $\eta$ expression was observed at day seven along with an increase in OC, ALP, and BSP. PKC $\eta$ was non-detectable at days 9, 11 and 13 . This isoform again reappeared at day 15 with an expression level $\sim 50 \%$ of the expression observed at day 1 . This reappearance correlated with an increase in OBC phenotypic markers. PKC $\theta$ was detected at day 1 of cell culture and was considerably down-regulated thereafter (Fig. 4).

Intracellular translocation of PKC $\theta$ and $\eta$ upon osteogenic stimulation. The possible role of PKC $\eta$ and $\theta$ in $\mathrm{OBC}$ differentiation was additionally investigated by comparing the intracellular translocation of osteogenically stimulated PKC $\eta$ to that of PKC $\theta$. Cells grown in osteogenic media on coverslips were examined along with matched controls by immunofluorescence using isoform-specific antibodies and phase contrast microscopy. The results demonstrate that PKC $\theta$ is seen concentrated in the perinuclear area prior to osteogenic stimulation and significantly down-regulated after osteogenic stimulation. PKC $\eta$ is observed to be significantly up-regulated and concentrated in the nuclei of osteogenic-stimulated osteoblastic cells as compared to that of control. Therefore, the immunofluorescence results in Fig. 5 add support to previous data observed for the involvement of PKC $\eta$ and $\theta$ in osteoblastic cells differentiation.

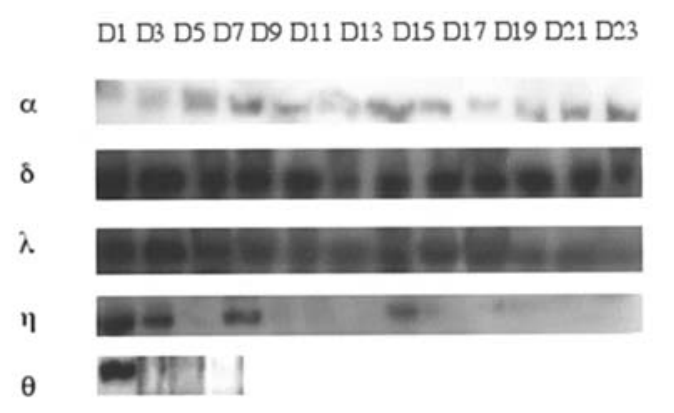

Days in Culture

Figure 3. Expression pattern of PKC isoforms in MC3T3-E1 osteoblastic cells. Western blot analyses of whole cell lysates retrieved from days 1-23 of MC3T3-E1 osteoblastic cell cultures were carried out using anti-PKC $\alpha$, $\beta, \gamma, \delta, \varepsilon, \lambda, \eta$ and $\theta$ monoclonal antibodies. Each blot is representative of 3 separate experiments with similar results. A similar blot for PKC $\eta$ and $\theta$ were scanned and the data are presented as graphs in Fig. 4.

The effect of p38 inhibitor SB203580 treatment on PKC $\eta$ and $\alpha$. To further delineate the involvement of PKC $\eta$ in osteoblastic differentiation, the p38 inhibitor SB203580 was used and its effects on alkaline phosphatase activity and PKC $\eta$ and $\alpha$ was determined at day 1 and day 7. The data show that the inhibition of p38 resulted in a decrease in alkaline phosphatase activity and a marked down-regulation of PKC $\eta$ at both day 1 and day 7 while this inhibitor of osteoblastic differentiation had little effect on PKC $\alpha$ (Fig. 6).

\section{Discussion}

The expression pattern of PKC isoform during osteoblastic cell differentiation was determined using the MC3T3-E1 in vitro model of osteogenesis. The MC3T3-E1 cell line has been demonstrated to be a useful cell system in studying osteoblastic cell differentiation $(25,26)$ and these cells, cultured in the presence of $\beta$-glycerol phosphate and ascorbic acid, differentiate in a sequential pattern to mature osteoblast. Specific protein markers are expressed in a temporal fashion during each osteoblastic differentiation stage. This temporal expression was used to determine the specific isoform of PKC involved in osteoblastic cell differentiation.

Our previous studies, along with those of others (20), have demonstrated that there is a specific pattern of PKC isoform expression in osteoblastic cells that depends on the source of the osteoblastic cells. The expression profile of the isoforms is cell-specific with differences observed between species and among primary versus transformed osteoblastic cells. In the present study, the expression profile of PKC isoforms is also shown to be dependent upon the stage of differentiation. Similarly to the osteoblastic cells previously tested, PKC $\alpha, \delta$ and $\lambda$ were found to be highly expressed. The expression of PKC $\theta$ was dependent upon stage of differentiation. PKC $\eta$, which was not previously tested, was also found to be highly expressed by these cells. PKC $\beta$ and $\varepsilon$ were only weakly detected when compared to PKC isoform positive controls.

The present study provides evidence that multiple isoforms from a single PKC class are expressed in MC3T3-E1 cells. The profile of expression for PKC isoforms has been 

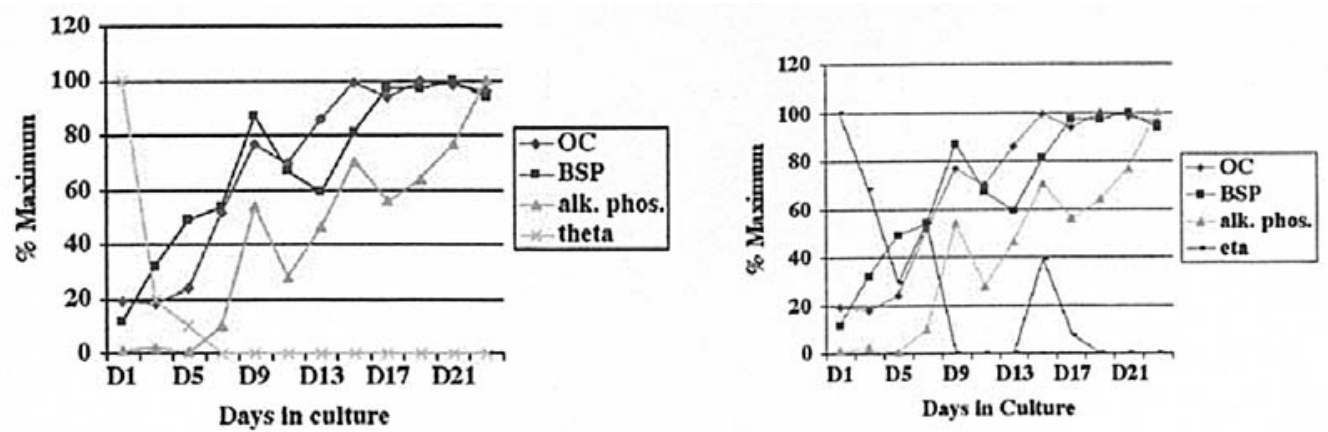

Figure 4. Correlation of the effect of osteogenic media on differentiation markers and PKC $\theta$ and $\eta$ expression in MC3T3-E1 cells. The cells were stimulated from day 1 to day 23 with $\alpha$-MEM supplemented with $10 \mathrm{mM} \mathrm{B-glycerophosphate,} 50 \mathrm{mM}$ ascorbic acid and $10 \mu \mathrm{M}$ dexamethasone and OBC differentiation markers and PKC isoform expression were determined as indicated in Materials and methods. Western blot and semi-quantitative RT-PCR analyses were carried out. The resultant blots were scanned and quantified by densitometry (left) PKC $\theta$ (right) PKC $\eta$. The results are from one representative blot of 3 separate experiments with similar results.

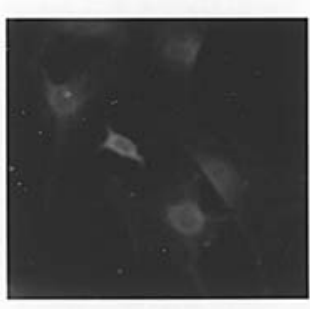

$$
\begin{aligned}
& \text { PKC } \theta \\
& \text { control }
\end{aligned}
$$
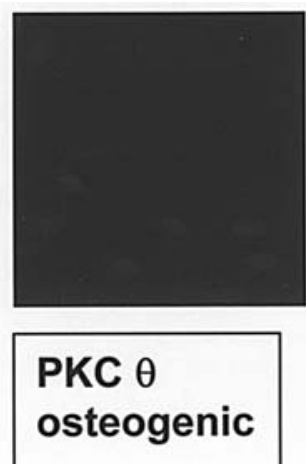

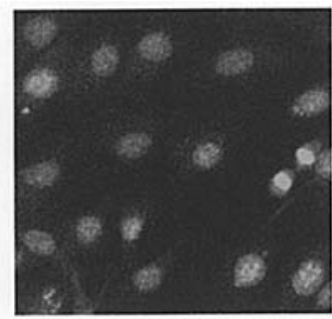

PKC $\eta$ Control
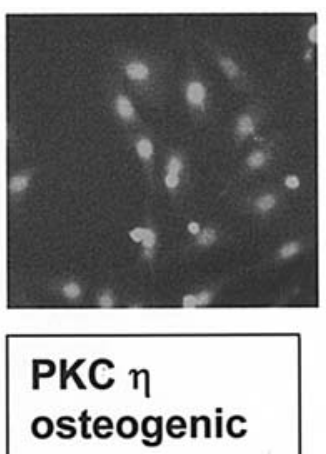

Figure 5. Intracellular expression of PKC $\theta$ and $\eta$ upon osteogenic stimulation. MC3T3 cells grown in osteogenic and non-osteogenic media were allowed to attach to cover slips for $24 \mathrm{~h}$. The cells were then fixed with $2 \%$ formaldehyde, permeabilized, and blocked for non-specific binding. The cells were incubated with specific primary antibody then with FITC conjugated secondary antibody. A fluorescence microscope was used to observe the intracellular translocation of the PKC isoforms of stimulated and non-stimulated cells (left 2 panels) PKC $\theta$ (right 2 panels) PKC $\eta$.

observed previously in primary rat osteoblastic cells as well as in a number of transformed osteoblastic cells. In contrast, only one member from each PKC class was detected in the primary human osteoblast (22). Thus, it still remains possible that in the primary rat, transformed lines as well as, in MC3T3-E1 osteoblastic cells, that multiple isoforms of PKC are in large part functionally redundant. However, differences that exist among the classes of PKC isoforms have identified several distinct mechanisms, which impart specificity to the action of individual isoforms $(23,27,28)$. PKC isoform diversity could convey a high degree of specificity, as well as flexibility to the mechanism of signaling in osteoblastic cells.

The particulars of function of different members of the PKC family are becoming increasingly lucid $(29,30)$. The present study delineates which particular isoforms are expressed by MC3T3-E1 cells; and correlates the expression profile of the isoforms to protein markers of the osteoblast differentiation process. Western blot analysis was used to determine which PKC isoforms are expressed during distinct phases of MC3T3-E1 osteoblast development. RT-PCR was used to assess the stage of osteoblast differentiation by looking at genes associated with the proliferation, differentiation and mineralization phases.

The initial stage of pre-osteoblastic MC3T3-E1 cell cultures has been well characterized as having highly proliferating cells, displaying fibroblastic morphology (Fig. 2) and low bone ALP levels (Fig. 1A). During these early proliferative stages, high levels of expression of PKC $\alpha, \delta, \lambda, \theta$ and $\eta$ were found. PKC $\alpha$ demonstrated the expression pattern that correlated best with the early markers of the OBC phenotype. The expression of PKC $\alpha$ continued to increase throughout the proliferative stages of MC3T3-E1 OBC. This pattern of expression is in accord with previous studies $(22,31)$. In primary rat $\mathrm{OBC}$ there is a continuous increase in PKC $\alpha$ expression from early to late cell cultures. Geng et al also demonstrated a marked increase in the level of cPKC- $\alpha$ expression in rat osteogenic sarcoma cells (UMR-108) upon cellular confluency (32).

PKC $\eta$ and $\theta$ expression displays the most dramatic pattern during the differentiation of MC3T3-E1 cells from the preosteoblastic to the mature osteoblastic phenotype. While the cells continued to express the isoforms $\alpha, \delta$ and $\lambda$ throughout the maturation process, PKC $\theta$ is significantly down-regulated. During the time of the differentiation process in which MC3T3-E1 exit the cell cycle, the expression of the $\theta$ isoform is down-regulated to a non-detectable level by day 7. A similar expression pattern of PKC $\theta$ has been reported on transcriptional level using gene array analysis in studying the differentiation of MC3T3-E1 cells (33). This suggests that PKC $\theta$ may play an inhibitory role in osteogenesis if it is not a consequence of osteoblastic differentiation itself. Studies on the 
A. Day 1

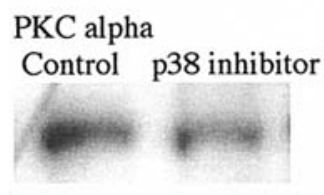

PKC eta Control p38 inhibitor

B. Day 7

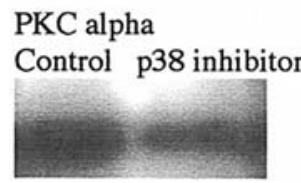

C. Alkaline Phosphatase Activity

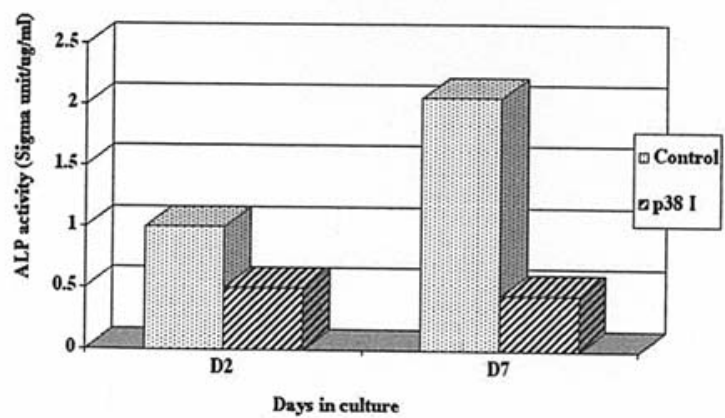

Figure 6. The effect of p38 inhibitor (SB203580) treatment on PKC $\alpha, \eta$, and alkaline phosphatase activity. The effect of the inhibition of P38 MAPK on osteoblastic cell differentiation was determined by treating MC3T3 cell cultures with $10 \mu \mathrm{M}$ of SB203580 for four days. After day 4 the cells were cultured in osteogenic media for the remainder of the culture period. WB technique previously described was used to evaluate the expression of the PKC $\eta$ and $\alpha$. Alkaline phosphatase activity was monitored via enzymatic methods, (A) control (B) p38 inhibitor (C) alkaline phosphatase.

role of $\mathrm{PKC} \eta$ in $\mathrm{OBC}$ are limited, however Sanders and Stern demonstrated the differential expression of PKC $\eta$ in osteoblastic cells and noted that the variability in expression may be due to the stage of differentiation of the screened osteoblasts (20). During the initiation of the osteoblast to the differentiation phase there are marked increases in the mRNA levels of OC, BSP and in bone ALP activity which parallel a significant increase in PKC $\eta$ at day 7. However, during the differentiation phase at days $9-15$ of cell culture, $\mathrm{PKC} \eta$ is non-detectable.

The mineralization phase (final phase) of MC3T3-E1 OBC maturation begins at approximately days 15-17 of cell culture. Other studies have referred to this time point in culture as the late mineralization stage (1) and as the final maturation phase (2). Our present work demonstrates that OBC up-regulates the expression of PKC $\eta$ at the initiation of the mineralization phase at day 15. This increase in PKC $\eta$ expression is paralleled by a marked increase in alkaline activity, OC and BSP mRNA levels (Fig. 4B). During the phase of active extracellular matrix mineralization characterized by nodule formation, maximum peak of expression of OC, BSP and peak in bone ALP activity, another peak in the expression of PKC $\alpha$ was detected, which occurred at day 21 . Both PKC $\eta$ and $\theta$ were non-detectable at this stage. The noted morphological changes observed in the cell culture during this stage are in accord with previous studies and are suggestive of post-mitotic matrix producing osteoblastic cells involved in mineralization.

The expression level of PKC $\eta$ peaked at the initiation of the proliferative phase and correlated with low levels of OBC differentiation protein markers. There were also marked increases in the expression of PKC $\eta$ at the initiation of the differentiation as well as the maturation phases of osteogenesis. These results suggest that PKC $\eta$ may be the candidate isoform involved in the initiation of the three phases of MC3T3-E1 OBC maturation. Further studies to ascertain the possible involvement of PKC $\eta$ in osteoblastic cell differentiation were therefore initiated. Immunofluorescence studies using phase contrast microscopy were performed to assess the intracellular translocation of PKC $\eta$ and $\theta$ upon osteogenic stimulation. In accord with the Western blot results, PKC $\theta$ was expressed throughout the cytoplasm and perinuclear area prior to osteogenic stimulation and this isoform was significantly down-regulated after osteogenic stimulation. PKC $\eta$ was observed to be up-regulated and appears to be concentrated within the nucleus upon osteogenesis.

$\mathrm{Hu}$ and coworkers (34) have demonstrated that p38 MAPK activity is required for osteoblastic differentiation in several cell cultures; including MC3T3-E1 cells. Therefore, SB203580 was used as a tool to inhibit p38 MAPK activity and determine the effect on alkaline phosphatase activity and PKC $\eta$ and $\alpha$ (the isoform previously demonstrated to be involved in OBC proliferation). The inhibition of p38 MAPK activity resulted in a marked decrease in PKC $\eta$ expression and had little effect on PKC $\alpha$ expression. The data also showed a significant decrease in alkaline phosphatase activity with p38 inhibition. These results, implicate PKC $\eta$ as the possible isoform involved in the differentiation of osteoblastic cell in part acting through the p38 MAPK pathway. PKC $\eta$ has been implicated in the control of proliferation and differentiation in other cell systems $(35,36)$. Cabodi and coworkers demonstrated that PKC $\eta$ was involved in growth suppression of keratinocytes and plays a role in the initiation of cellular differentiation (35). However, further studies are necessary in order to determine if these observed changes in PKC $\eta$ expression are an upshot of differentiation or play a regulatory role in the control of the differentiation process.

In summary, this study demonstrates that there is a specific expression profile of PKC isoforms in MC3T3 osteoblastic cells, which differs in their pattern of expression throughout the development of the cells. The expression pattern of PKC isoforms suggests possible specificity of function of individual isoforms in osteoblastic cells during the process of osteogenesis and may render novel regulatory approaches in the prevention and treatment of skeletal diseases.

\section{Acknowledgements}

This study was supported in part by grant R03 DE 014458 from the National Institutes of Health (NIH), National Institute of Dental and Craniofacial Research (NIDCR). 


\section{References}

1. Choi JY, Lee BH, Song KB, Park RW, Kim IS, Sohn KY, Jo JS and Ryoo HM: Expression patterns of bone-related proteins during osteoblastic differentiation in MC33T3-E1 cells. J Cell Biochem 61: 609-618, 1996.

2. Quarles LD, Yohay DA, Lever LW, Caton R and Wenstrup RJ: Distinct proliferative and differentiated stages of murine MC3T3-E1 cells in culture: An in vitro model of osteoblast development. J Bone Miner Res 7: 683-692, 1992.

3. Sudo H, Kodama H, Amagai Y, Yamamoto Y and Kasai S: In vitro differentiation and calcification in a new clonal osteogenic cell line derived from newborn mouse calvaria. J Cell Biol 96: 191-198, 1983

4. Owen TA, Aronow M, Shalhoub V, Barone LM, Wilming L, Tassinari MS, Kennedy, M, Pockwinse S, Lian JB and Stein GS: Progressive development of the rat osteoblast phenotype in vitro: Reciprocal relationships in expression of genes associated with osteoblast proliferation and differentiation during formation of the bone extracellular matrix. J Cell Physiol 143: 420-430, 1990.

5. Kitching R, Qi S, Li V, Raouf A, Vary CP and Seth A: Coordinate gene expression patterns during osteoblast maturation and retinoic acid treatment of MC3T3-E1 cells. J Bone Miner Res 20: 269-280, 2002.

6. Higuchi CM, Hashimoto N, Kuriyama K, Yoshioka K, Yoshikawa $\mathrm{H}$ and Itoh $\mathrm{K}$ : Continous inhibition of MAPK signaling promotes the early differentiation and mineralization of the extra cellular matrix. J Bone Miner Res 18: 67-77, 2002.

7. Engelman JA, Lisanti MP and Scherer PE: Specific inhibitors of p38 mitogen-activated protein kinase block 3T3-L1 adipogenesis. J Biol Chem 273: 32111-32120, 1998.

8. Zester A, Gredinger E and Bengal E: p38 mitogen-activated protein kinase pathway promotes skeletal muscle differentiation. Participation of the Mef2c transcription factor. J Biol Chem 274: 5193-5200, 1999.

9. Suzuki A, Palmer G, Bonjour JP and Caverzasio J: Regulation of alkaline phosphatase activity by p38 MAP kinase in response to activation of $\mathrm{Gi}$ protein-coupled receptors by epinephrine in osteoblast-like cells. Endocrinology 140: 3177-3182, 1999.

10. Vinals F, Lopez-Rovira T, Rosa JL and Ventura F: Inhibition of $\mathrm{PI} 3 \mathrm{~K} / \mathrm{p} 70 \mathrm{~S} 6 \mathrm{~K}$ and $\mathrm{p} 38$ MAPK cascades increases osteoblastic differentiation induced by BMP-2. FEBS 510: 99-104, 2002.

11. Dziak R, Dahman M and Lampasso J: Osteoblastic cell differentiation and p38 MAP kinase. Bone 36: S287, 2005.

12. Munakata M, Stamm C, Friehs I, Zurakowski D, Cowan DB, Cao-Danh H, McGowan FX Jr and Del Nido PJ: Protective effects of protein kinase $\mathrm{C}$ during myocardial ischemia require activation of phosphatidyl-inosiitol specific phospholipase C. Ann Thorac Surg 73: 1236-1245, 2002.

13. Denning MF, Dlugosz AA, Cheng C, Dempsey PJ, Coffey RJ Jr, Threadgill DW, Magnuson T and Yuspa SH: Cross-talk between epidermal growth factor receptor and protein kinase $\mathrm{C}$ during calcium-induced differentiation of keratinocytes. Exp Derm 9: 192-199, 2000.

14. Wetsel WC, Khan WA, Merchenthaler I, Rivera H, Halpern AE, Phung HM, Negro-Vilar A and Hannun YA: Tissue and cellular distribution of the extended family of Protein kinase C isoenzymes. J Cell Biol 117: 121-133, 1992.

15. Brandlin I, Hubner S, Eiseler T, Martinez-Moya M, Hausser A, Horschinek A, Link G, Rupp S, Storz P, Pfizenmaier K and Johannes FJ: Protein kinase C (PKC) eta-mediated mu activation modulates ERK and JNK signal pathways. J Biol Chem 277: 6490-6496, 2002.

16. Langzam L, Koren R, Gal R, Kugel V, Paz A, Farkas A and Sampson SR: Patterns of protein kinase C isoenzyme expression in transitional cell carcinoma of bladder. Relations to degree of malignancy. Am J Clin Path 116: 377-385, 2001.

17. Meldrum DR, Cleveland JC Jr, Meng X, Sheridan BC, Cain BS, Gamboni F, Harken AH and Banerjee A: Protein kinase C isoform diversity in preconditioning. J Surg Res 69: 183-187, 1997.
18. Delannoy P, Lemonnier J, Hay E, Modrowski D and Marie PJ: Protein kinase C-dependent upregulation of $\mathrm{N}$-cadherin expression by phorbol ester in human calvaria osteoblasts. Exp Cell Res 269: 154-161, 2001

19. Hakeda Y, Shiokawa M, Mano H, Kameda T, Raisz L and Kumegawa M: Prostaglandin $\mathrm{F}_{2} \alpha$ stimulates tyrosine phosphorylation and mitogen-activated protein kinase $\mathrm{C}$ activation. Endocrology 138: 1821-1828, 1997.

20. Sanders J and Stern P: Expression and phorbol ester-induced down-regulation of protein kinase $\mathrm{C}$ isozymes in osteoblasts. J Bone Miner Res 11: 1862-1872, 1996.

21. Lampasso JD, Intini G and Dziak M: Effects of 1,25 Dihydroxyvitamin D3 on PKC isoform expression in osteoblastic cells. Int $\mathrm{J}$ Oral Biol 25: 65-73, 2000.

22. Lampasso JD, Marzec N, Margarone J and Dziak M: Sphingosine1-phosphate effects on PKC isoform in human osteoblastic cells. Prostaglandins Leukot Essent Fatty Acids 3: 1139-1146, 2001.

23. Sakai T, Okano Y, Nozawa Y and Oka N: Different Protein kinase $\mathrm{C}$ isozymes could modulate bradykinin-induced extracellular calcium-dependent and -independent increases in osteoblast-like MC3T3-E1 cells. Cell Calcium 13: 329-340, 1992.

24. Bessey O, Lowry OH and Brock MJ: A method for the rapid determination of alkaline phosphatase with five cubic millimeters of serum. J Biol Chem 164: 321-325, 1946.

25. D'Alonzo RC, Kowalski AJ, Denhart DT, Nickols GA and Partridge NC: Regulation of Collagenase-3 and osteocalcin gene expression by collagen and osteopontin in differentiating MC3T3-E1 cells. J Biol Chem 277: 24788-24798, 2002.

26. Vary CPH, Li V, Raouf A, Kitching R, Ismail K, Franceschi C, Venanzoni $\mathrm{M}$ and Seth A: Involvement of Ets transcription factors and targets in osteoblast differentiation and matrix mineralization. Exp Cell Res 257: 213-222, 2000

27. Mathews SA, Rozengurt E and Cantrell D: Protein kinase D. A selective target for antigen receptors and a downstream target for protein kinase C in lymphocytes. J Exp Med 191: 2075-2082, 2000.

28. Asado A, Zhao Y and Kondo S: Iwata M. Induction of thymocyte apoptosis by $\mathrm{Ca} 2+-$-independent protein kinase $\mathrm{C}$ (nPKC) activation and its regulation by calcineurin activation. J Biol Chem 273: 28392-28398, 1998.

29. Chen CC, Wang JK and Lin SB: Antisense oligonucleotides targeting protein kinase $C-\alpha,-\beta 1$, or $-\delta$ but not $-\eta$ inhibit lipopolysacharide-induced nitric oxide synthase expression in RAW 264.7 macrophages: involvement of a nuclear tactor kBdependent mechanism. J Immunol 161: 6206-6214, 1998.

30. Chen L, Hahn H, Wu G, Chen CH, Liron T, Schechtman D, Cavallaro G, Banci L, Guo Y, Bolli R, Dorn GW 2nd and Mochly-Rosen D: Opposing cardioprotective actions and parallel hypertrophic effects of delta PKC and epsilon PKC. Proc Natl Acad Sci USA 98: 11114-11119, 2001.

31. Lampasso JD, Marzec N, Margarone J and Dziak M: Role of protein kinace C- $\alpha$ in primary human osteoblast proliferation. J Biomed Mater Res 17: 1968-1976, 2002.

32. Geng WD, Boskovic G, Fultz ME, Li C, Niles RM, Ohno S and Wright GL: Regulation of expression and activity of four PKC isozymes in confluent and mechanically stimulated UMR-108 osteoblastic cells. J Cell Physiol 189: 216-228, 2001.

33. Beck GR, Zerler B and Moran E: Gene array analysis of osteoblast differentiation. Cell Growth Differ 12: 61-83, 2001

34. Hu Y, Chan E, Wang SX and Li B: Activation of p38 mitogenactivated protein kinase is required for osteoblast differentiation. Endocrinology 144: 2068-2074, 2003.

35. Cabodi S, Calautti E, Talora C, Kuroki T, Stein PL and Dotto GP: A PKC-eta/Fyn-dependent pathway leading to keratinocyte growth arrest and differentiation. Mol Cell 6: 1121-1129, 2000.

36. Livneh E, Shimon T, Bechor E, Doki Y, Schieren I and Weinstein IB: Linking protein kinase $\mathrm{C}$ to the cell cycle: ectopic expression of PKC eta in NIH3T3 cells alters the expression of cyclins and Cdk inhibitors and induces adipogenesis. Oncogene 12: 1545-1555, 1996. 